INTERNATIONAL JOURNAL OF MULTIDisciplinARY RESEARCH AND ANALYSis

ISSN(print): 2643-9840, ISSN(online): 2643-9875

Volume 05 Issue 02 February 2022

DOI: 10.47191/ijmra/v5-i2-15, Impact Factor: 6.072

Page No. $338-342$

\title{
Information and Communication Technology (ICT) Skill and Quality Medical Care in Federal Medical Centre, Owo, Ondo State, Nigeria
}

\author{
Soyemi, Opeyemi D. ${ }^{1}$, Akindele, Akinade Frederick ${ }^{2}$ \\ 1,2Information Resources Management Department Babcock University, Ilishan-Remo, Nigeria
}

\begin{abstract}
Quality medical care connotes a medical service with inherent ability to meet desired health outcome. Quality medical care is of concern to everyone. This is because it is important to human welfare and efficiency. The situation in Nigeria's hospitals as depicted in literature and observed by many is worrying. The quality of medical care services available in the Federal Medical Centres (FMCs) in Nigeria is worrisome and of concern to everyone. Empirical evidences in literature have shown that Information and Communication Technology (ICT) skill has positive impact on several professional output including medical service. It is believed that ICT proficiency of medical practitioners could contribute to a higher quality of medical care services. This study therefore examined the influence of ICT skill on the quality of medical care in FMC Owo, Nigeria.

Method: The study is based on post-positivist epistemology. Quantitative research method and survey research design were adopted. Out of the 95 population of medical doctors, a total of 76 of them, obtained through Krejcie and Morgan sample size table, were surveyed using convenience sampling technique. The doctors were surveyed using a five scale Likert-like adapted structured questionnaire research instrument and a 95\% return rate was achieved.

Results: The study found that ICT skill positively and significantly influenced quality of medical care with a $P$ value of 0.000 ( $p<0.05$ ) in FMC Owo, Nigeria. This shows that there is a positive and significant influence of ICT skill on quality medical care. The quality of medical care in the hospital is good with an overall mean of 3.35 on the scale while the level of ICT skill among doctors is high with an overall mean of 3.84 .

Conclusion: The study concluded that ICT skill has positive and significant influence on quality of medical care. Therefore, there is need to sharpen the ICT skill of medical practitioners through government and institutional support towards sustaining and further improving the present medical care quality.
\end{abstract}

KEYWORDS: Digital Literacy, Federal Medical Centre, Information and Communication Technology Skill, Medical Care, Nigeria, Owo, Quality medical care.

\section{INTRODUCTION}

Quality medical care is the degree to which medical care services rendered to patients meet the desired health outcome (WHO, 2020). Every patient desires standard medical care services rendered in the most professional way to guarantee quick restoration of health and capacity. This desire requires that medical care services must be safe, efficient, timely, effective, accessible, patientcentred, responsive, acceptable, affordable and reliable. Achieving this demands an all-inclusive approach as advanced by the Donabedian's SPO theory of quality medical care. The SPO theory of quality medical care explains the phenomenon of achieving the desired medical outcome through the establishment and interplay of good structure and process.

This means that adequate structure and process results in the desired medical outcome. Structure refers to the array of resources such as adequate physical buildings, furniture, equipment, drugs, medical consumables, right personnel and machines. While process is the activities of the medical care givers in translating the resources into services in an acceptable way. It includes: arrangement for doctor-patient consultation treatments, reasonable patient waiting time, friendliness of staff, responsiveness to patients' requests/needs, physical and clinical examination, empathy, referral system, effectiveness, professionalism, effective communications, pre-packing of medicines, pharmacological services, counselling, efficiency, appointment system, defaulter tracking and attendance to patients. Finally, the outcome is the end-result of the interplay between structure and process manifesting in the restoration of health, patient satisfaction, commendation of care-givers, patronage, referral of others, cooperation, good quality of life, good health-seeking behaviours and reduction in complaints. 


\section{Information and Communication Technology (ICT) Skill and Quality Medical Care in Federal Medical Centre, Owo, Ondo State, Nigeria}

The quality of the medical care services available to patients in Nigeria is observed to be substandard (Ameh et al., 2020; Akindele, 2019; Odunaiya, Akinpelu, Ogwu, \& Aje, 2019; Ephraim-Emmanuel, Adigwe, Oyeghe \& Ogaji, 2018; Izugbara \& Wekesah, 2018). Most physical facilities such as buildings are not built to suit purpose and are poorly maintained, infrastructure such as electricity and access road to and within the hospital are in deplorable states. Many of the hospitals as well as citizens' residences lack portable water supply, most hospital equipment are obsolete, dysfunctional and inadequate for today's medical practice, there is inadequate staffing and poorly motivated staff in terms of timely remunerations as well as staff motivation factors such as training and reward system. Also, affordability and availability of drugs and consumables required to effectively treat patients is a mirage in many of the hospitals. There is compromise of safety of patients from harm or threat of harm, patient waiting time is unreasonably long, most hospital staff are unfriendly and irresponsive to the needs of the patients, lack of empathy is a common phenomenon and the referral system is deficient (Odunaiya, Akinpelu, Ogwu, \& Aje, 2019).

The consequences of this poor quality medical care services is enormous. Among them are loss of lives, incapacitations, loss of hospital reputation and patronage, loss of revenue, increased healthcare cost burdens on individuals and governments, loss of individual national productivity, poverty, crime and social unrest.

Information and Communication Technology (ICT) is an equipment that integrates telecommunications, computers, storage devices and application software for the creation, transmission, access, manipulation and use of information resources. It is the equipment and accessories used for modern computing. Although there is no universally accepted definition of ICT, it is widely accepted as any device, network resources, application software and systems that are integrated to promote interactions in today's digital world. United Nations Educational, Scientific and Cultural Organization (UNESCO) defines ICT as the forms of technology that are used to transmit, process, store, create, display, share or exchange information by electronic means (UNESCO, 2019). ICT is sometimes used synonymously with Information Technology (IT). However, ICT is generally used to represent a wider and more comprehensive list of all components related to computer and digital technologies than IT. This is because while IT is only limited to information devices, ICT integrates telecommunication devices into Information equipment thereby making it more robust and comprehensive that IT.

ICT skill is the ability to accept, use and produce digital contents using Information and Communication Technology (Noh, 2016). It is the ability to use Information and Communication Technology (ICT) tools to find, locate, manage, integrate, evaluate, create, communicate and share information necessary for relevance and success in today's knowledge society (Sharma, Fantin, Prabhu, Guan \& Dattakumar, 2016). Therefore, to be digitally literate, someone must possess information, communication, photovisual, reproduction as well as socio-emotional and real-time skills (Eshet-Alkalai, 2012). According to Kennedy and Yaldren (2017), ICT skill in healthcare is measured using the competencies of medical practitioners in data/information, digital branching and communication, collaboration/real-time, socio-emotional/safety, media/photo-visual, reproduction skills.

Many scholars believe the efficient application of ICT in healthcare can help improve the quality of medical care. However, it will be almost impossible to appropriate and maximize the potential benefits of ICT when its technical know-how is not understood. It therefore become important to understand the technology and how it can help address quality issues in medical care before its benefits can be appropriated. Unfortunately, the condition is different in Africa, especially Nigeria where most of the citizens are not ICT literate due to several reasons. Some of the reasons include poverty, inequality, sociocultural barriers, language and the generally high level of illiteracy. Most Nigerians lack personal computers while several million others have no formal education (Ifijeh, Iwu-James \& Adebayo, 2016).

In view of the assumption that ICT skill influences the quality of medical care and the gap in literature as to the truthfulness of this assertion in FMCs in Nigeria, this study became necessary to:

1. Identify the quality of medical care services in FMC Owo, Nigeria;

2. Identify the level of ICT skill among doctors in FMC Owo, Nigeria; and

3. Determine the influence of ICT skill on the quality of medical care services in FMC Owo, Nigeria.

The researcher hypothesized that ICT skill does not significantly influence the quality of medical cares in FMC Owo, Nigeria. This research assumption was subjected to statistical tests using empirical data to confirm or refute the assumptions at 95 percent (95\%) level of confidence $(\mathbf{P}<=\mathbf{0 . 0 5})$.

\section{METHOD}

This study adopted a survey research design. The population of the study are the 95 medical doctors in the Hospital as obtained from the office of the Chief Medical Director of the hospital. Using the Krejcie and Morgan table for sample size calculation, a total of 76 samples were reached. This total of 76 medical doctors in the FMC were surveyed using convenience sampling technique in view of varied duty schedules and difficulty to find study participants. Survey data for the study was collected using the 

Ondo State, Nigeria

questionnaire instrument. The questionnaire on ICT skill was adapted from the work of Son, Park and Park (2017) while the one on quality of medical care was adapted from the work of Marshall and Hays (1994). The adapted structured instrument is a fivepoint likert-like scale which was subjected to validity and reliability tests to enhance the credibility of the study. Reliability test of the instrument was done using the Cronbach's Alpha tests. This returned Cronbach's Alpha score of 0.98 for ICT skill of Doctors and 0.96 for quality of medical care. This suggested a high level of internal consistency among the survey items used in the study.

Data collection was done over a period of 2 weeks with the help of a trained research assistant. Data analysis was done using the Statistical Product and Services Solution (SPSS) version 21. Data from the returned questionnaires were collected, collated and inputted into the computer system. Descriptive statistical analyses were carried out to describe the pattern of occurrence of the phenomena under investigation. Also the influence of ICT on quality of medical care phenomena was analyzed using simple linear regression analysis. This informed the inferences and conclusions that was drawn in the study.

Ethical approval was obtained from the research ethics committee with number: BUHREC 292/21 dated $6^{\text {th }}$ April, 2021. Respondents were given time to review the consent form and ratify it before proceeding with the survey. Confidentiality of respondents was protected and survey data was properly secured in locked cabinets and pass-worded personal computer.

\section{RESULTS}

72 out of the 76 questionnaires were returned and fit for use making a 95\% return rate. Out of the 72 medical doctors surveyed, $75 \%(n=54)$ are male while the remaining $25 \%(n=18)$ are female. $50 \%$ of the doctors are within the ages of $31-45$ years $(n=36)$ with $70 \%(n=50)$ having less than 11 years clinical experience. Most $28 \%(n=20)$ of them are also medical officers and the least $3 \%$ $(n=2)$ have attained the highest rank of Chief Consultant.

A Decision Rule of 1.0 - 1.7 = Very Poor; 1.8 - 2.5 = Poor; 2.6 - 3.3 = Fair; 3.4 - 4.1 = Good; 4.2-5.0 = Very Good was developed for the study and the quality of medical care services has an overall mean of 3.35 on the scale. This means that the quality of medical care in FMC Owo is good.

Similarly, with a decision rule of $1.0-1.7=$ Very Low; $1.8-2.5=$ Low; $2.6-3.3=$ Moderate; $3.4-4.1=$ High; $4.2-5.0=$ Very High, the level of ICT skill has an overall mean of 3.84. This means that the level of ICT skill among doctors in FMC Owo, Nigeria is high. Lastly, ICT skill positively and significantly influenced quality of medical care with a P value of $0.000(p<0.05)$ in FMC Owo, Nigeria. This shows that there is a positive and significant influence of ICT skill on quality medical care in FMC, Owo.

Table 1. The influence of ICT skill on quality of medical care in FMC Owo.

\begin{tabular}{|l|l|l|l|l|l|l|l|}
\hline Variables & Beta ( $\boldsymbol{\beta})$ & $\mathbf{T}$ & Sig. & $\mathbf{R}^{\mathbf{2}}$ & Adj. $\mathbf{R}^{\mathbf{2}}$ & $\mathbf{F}$ & $\mathbf{p}$ \\
\hline (Constant) & & 11.843 & .000 & 0.063 & 0.060 & 19.436 & 0.000 \\
\hline ICT Skill & .252 & 4.409 & .000 & & & & \\
\hline Dependent Variable: Quality of Medical Care \\
Predictor: ICT Skill \\
DF (F-Statistic) $=1,71$ \\
DF (T-Statistic) $=72$
\end{tabular}

\section{DISCUSSION OF FINDINGS}

The study found that most of the medical doctors in the study area are males. This demographic finding is in line with the data from the register of Medical and Dental Council of Nigeria which says only 35\% of the total 74,543 medical doctors in Nigeria are females. Similarly, most of these medical practitioners have less than 11 years' work experience probably because of high rate of medical brain drain in the country (Kirigia, Gbary, Nyoni, Seddoh \& Muthuri, 2006).

Surprisingly, the quality of medical care in the FMC under study was found to be good contrary to the results from many other empirical studies such as those of Ameh, et al (2020); Odunaiya, Akinpelu, Ogwu and Aje (2019) and Odetola and Fakorede (2018) which discovered that the quality of medical care in Nigeria's hospitals is poor. However, the finding may be a confirmation of the work of Roder-Dewan, et al (2019) which submitted that patients in Nigeria are often satisfied with low quality service (RoderDewan, et al, 2019). This may also be a confirmation of the argument that several investments in the healthcare system by the government and non-governmental organizations are beginning to yield positive results. 


\section{Information and Communication Technology (ICT) Skill and Quality Medical Care in Federal Medical Centre, Owo, Ondo State, Nigeria}

In the same vein, contrary to widespread opinions, the level of ICT skill among doctors in FMC Owo, Nigeria is found to be high. This contradicts the findings from the works of Hassan (2019) as well as that of Kanjo and Kaasboll (2019). However, this might have been explained by the result of the work of Porat, Blau and Barak (2018) where the researchers discovered that staff often over-estimate their ICT capability (Porat, Blau \& Barak, 2018). It is also important to note that this category of Nigerians are literate and highly skilled by virtue of their medical training. This may have informed their personal and professional development as well as ICT capacity enhancement.

The study found a significant relationship between ICT skill and the quality of medical care. This supports the findings of Blumer and Primmer (2019) and that of Kennedy and Yaldren (2017).

\section{CONCLUSION}

Although the level of the quality of medical care in FMC Owo is considered high, there is need for its further improvement towards achieving the desired very high quality medical care. This, if achieved, will reassure citizens and restore their hope in the Nigeria's medical care system. The result of the influence of ICT skill on quality of medical care in this study has shown that the desired quality of medical care can be achieved if more investments can be made to enhance the ICT competence of the medical care providers in the hospital. Government and hospital management should therefore encourage improved ICT competence among medical care providers by providing adequate number of ICT devices for them to work as well as subsidize personal ones for them to acquire. Further studies to ascertain the ICT skill claims of medical doctors through practical engagements should be conducted in future.

\section{REFERENCES}

1) Akindele, A. F. (2019). The significance of Electronic Health Records (EHR) to the Reduction of Patient Safety Events (PSEs) in the Hospital. Anatolian Journal of family medicine, 2(1), 17-26.

2) Ameh, S., Akeem, B. O., Ochimana, C., Oluwasanu, A., Mohamed, S. F., Okello, S., . . Danaei, G. (2020, May). Access to and quality of primary healthcare: A multi-country qualitative case study in West and East Africa. doi:10.21203/rs50542/v1

3) Blumer, E., \& Pimmer, C. (2019). Health professionals' communication on social media and digital literacy: Findings from a systematic review. Europian Conference on Health Communication. Zurich.

4) Ephraim-Emmanuel, B., Adigwe, A., Oyeghe, R., \& Ogaji, D. S. (2018). Quality of healthcare in Nigeria: a myth or a reality. International Journal of Research in Medical Sciences, 6(9). doi:10.18203/2320-6012.ijrms20183621

5) Eshet-Alkalai , Y. (2012). Thinking in the digital Era: A revised model for digital literacy. Issues in Information Science and Information Technology, 9(1), 267-276.

6) Hassan, Z. (2019, February 6). Digital Literacy - a blind spot in medical education. Retrieved from Bmj.com: www.googletagmaster.com/ns.html?id=GTM-N6kc289

7) Ifijeh, G., Iwu-James, J., \& Adebayo, O. (2016). Digital inclusion and sustainable development in Nigeria: The role of libraries. 3rd International Conference on Africa Development Issues (CU-ICADI 2016) (pp. 52-57). Sango-Ota, Nigeria: Covenant University Press.

8) Izugbara, C. O., \& Wekesah, F. (2018). What does quality maternity care mean in a context of medical pluralism? Perspective of women in Nigeria. Oxford Journals Health Policy Plan, 33(1), 1-8. doi:10.1093/heapol/czx131

9) Kanjo, C., \& Kaasboll, J. (2019). Digital empowerment for health workers and its implication on the use of EHR. Health Informatics Conference (HELINA) 2019. Gaborone, Botswana.

10) Kennedy, S., \& Yaldren, J. O. (2017). Digital Literacy: Technology feature. British Journal for Cardiac Nursing, 12(9), 3138.

11) Kirigia, J. M., Gbary, A. R., Nyoni, J., Seddoh, A., \& Muthuri, L. K. (2006). The cost of high-related brain drain to the WHO African Region. African Journal of Health Science, 13(1), 1-12.

12) Marshall, G. N., \& Hays, R. D. (1994). The Patient Satisfaction Questionnaire Short-Form (PSQ-18). Santa Monica, Canada: RAND.

13) Noh, Y. (2016). A study on the effect of Digital Literacy on Information use behavior. Journal of Librarianship and Information Science, 8(16), 1-31.

14) Odetola, T. D., \& Fakorede, E. O. (2018). Assessment of perinatal care satisfaction amongst mothers attending post natal care in Ibadan, Nigeria. Ann Glob Health, 84(1), 36-46. doi:10.29024/aogh.10 
Information and Communication Technology (ICT) Skill and Quality Medical Care in Federal Medical Centre, Owo, Ondo State, Nigeria

15) Odunaiya, N. A., Akinpelu, A. O., Ogwu, S., \& Aje, O. (2019). Healthcare professionals' perception of the quality of healthcare of patients with Cardiac disease in Nigeria: Implication for clinical guideline, inter-professional education and teamwork. Malawi med. journal, 31(1), 31-38. doi:10.4314/mmj.v31i1.6

16) Porat, E., Blau, I., \& Barak, A. (2018). Measuring digital literacies: Junior high-school students' percieved competencies versus actual performance. Computer \& Education, 18(2), 1-33.

17) Roder-DeWan, S., Gage, A. D., Hirschhor, L. R., Twum-Danso, A. Y., Liljestrand, J., Asante-Shongwe, K., . . Kruk, M. E. (2019). Expectations of healthcare quality: A cross-sectional study of internet users in twelve (12) middle and low income countries. PLOS Med, 16(8). doi:10.1371/journal.pmed.1002879

18) Sharma, R., Fantin, A., Prabhu, N., Guan, C., \& Dattakumar, A. (2016). Digital literacy and knowledge societies: agrounded theory investigation of sustainable development. Telecommunications policy, 40(1), 628-643.

19) Son, J., Park, S., \& Park, M. (2017, October 29). Digital literacy of language learners in two different contexts. Retrieved from Semantic Scholar: https://www.semanticscholar.org/paper/Digital-literacy-of-language-learners-in-two-SonPark/2fa3ad971fe3227c9fdc439d2eff2eeaab1a5335

20) UNESCO. (2019). World Summit on Information Society: Forum 2019. ITU. Geneva.

21) WHO. (2020, January 7). What is quality of care and why is it important. Retrieved from who.int: www.who.int/maternalchild-adolescent/topics/quality-of-care/definition/en/ 